\title{
Exposure Flow Rate Unit of Measure
}

National Cancer Institute

\section{Source}

National Cancer Institute. Exposure Flow Rate Unit of Measure. NCI Thesaurus. Code C83072.

The unit of measure for the velocity or speed of an exposure. 